\title{
A case of newly diagnosed immune thrombocytopenia in the COVID-19 era
}

\author{
Bianca Clerici ${ }^{1}$. Simone Birocchi ${ }^{1}$. Elena Bertinato ${ }^{1}$. Clara Di Benedetto ${ }^{2} \cdot$ Sabrina Caberlon $^{1} \cdot$ Marco Cattaneo $^{1}$. \\ Gian Marco Podda ${ }^{1}$ (])
}

Received: 25 July 2020 / Accepted: 24 October 2020 / Published online: 12 November 2020

(c) Società Italiana di Medicina Interna (SIMI) 2020

A 64-year-old man presented to our Emergency Department (ED) in April 2020, in the midst of the COVID-19 pandemic, complaining of 3 days of unexplained fever following a contact with a known SARS-CoV-2 positive subject, atraumatic epistaxis and appearance of muco-cutaneous petechiae. At first medical contact, the patient was afebrile, showed no difficulty breathing in room air with a peripheral oxygen saturation of $95 \%$, and reported no symptoms attributable to SARS-CoV-2 infection. The past medical history included diabetes mellitus and arterial hypertension. The initial blood work-up showed isolated severe thrombocytopenia $\left(2 \times 10^{9} / \mathrm{L}\right)$, a hemoglobin value of $\mathrm{Hb} 13.2 \mathrm{~g} / \mathrm{dL}$ with MCV $87 \mathrm{fL}$, a white blood cell (WBC) count within normal limits, and a CRP of $11 \mathrm{mg} / \mathrm{L}$ (normal values $<10 \mathrm{mg} / \mathrm{L}$ ).

Dr. Clerici and Dr. Di Benedetto. The patient presented to the ED for fever and active bleeding; blood tests showed a newly discovered, unexplained thrombocytopenia. In this setting, the diagnostic approach to isolated thrombocytopenia is challenging and the emergent hematologic conditions, such as thrombotic microangiopathies (TMAs) and immune thrombocytopenia (ITP), must be carefully evaluated. In the patient described with severe thrombocytopenia and a probable infection, disseminated intravascular coagulation (DIC) is another potential cause of concern. During the COVID-19 outbreak in Northern Italy, the presence of fever following a contact with a SARS-CoV-2 positive subject was a finding of equal clinical importance: the patient needed to be tested for SARS-CoV-2 so as to be appropriately allocated in the hospital setting. Moreover, it must be noted that COVID-19

Gian Marco Podda

gmpodda@gmail.com

1 Divisione di Medicina Generale II, Dipartimento di Scienze della Salute, ASST Santi Paolo E Carlo, Università degli Studi di Milano, Via di Rudinì, 8, 20142 Milan, Italy

2 Divisione di Gastroenterologia ed Epatologia, ASST Santi Paolo e Carlo, Milan, Italy has been associated with the onset of DIC, but generally only in critically ill patients. Therefore, coagulation tests, including fibrinogen and D-dimer, hemolysis work up, and testing with the locally available rRT-PCR test for SARS-CoV-2 must be obtained in a timely manner.

Prothrombin time, activated partial thromboplastin time, fibrinogen and D-dimer were within normal limits. Furthermore, there were no signs of hemolysis, the patient's renal function was preserved and schistocytes were absent in the peripheral blood smear. The patient tested positive for SARS-CoV-2 at the first nasopharyngeal swab performed in the E.R. The chest X-ray showed a pattern of bilateral interstitial pneumonia, which was confirmed by chest computer tomography (CT) (Fig. 1), which also revealed the presence of two enlarged lymph nodes in the left axillary region.

Dr. Bertinato and Dr. Caberlon. The diagnosis of SARS$\mathrm{CoV}-2$ infection is confirmed. Although imaging findings of bilateral interstitial pneumonia are present, the patient is stable and does not require supplemental oxygen therapy. COVID-19 may be associated with thrombocytopenia, which, however, is generally mild [1]. TMAs have been ruled out. Similarly to other viral infections, SARSCoV-2 has been related to the onset of ITP, but only one case has been described [2]. Moreover, not all cases of ITP require specific treatment. In the presence of a platelet count $<30 \times 10^{9} / \mathrm{L}$ and of active bleeding, however, treatment initiation is required [3]. With consideration of thrombocytopenia severity and of the bleeding diathesis, a platelet pool transfusion can be considered as the patient's initial treatment. Monitoring of the platelet count shortly after a platelet pool transfusion may be of help to detect the presence of peripheral platelet destruction, and thus justify the initiation of ITP treatment, although the diagnosis has not yet been made. First-line treatment options for ITP include corticosteroids and intravenous immunoglobulin (IvIg); of the two, corticosteroids induce a more persistent increase in platelet count, and appear more suitable in this case. 


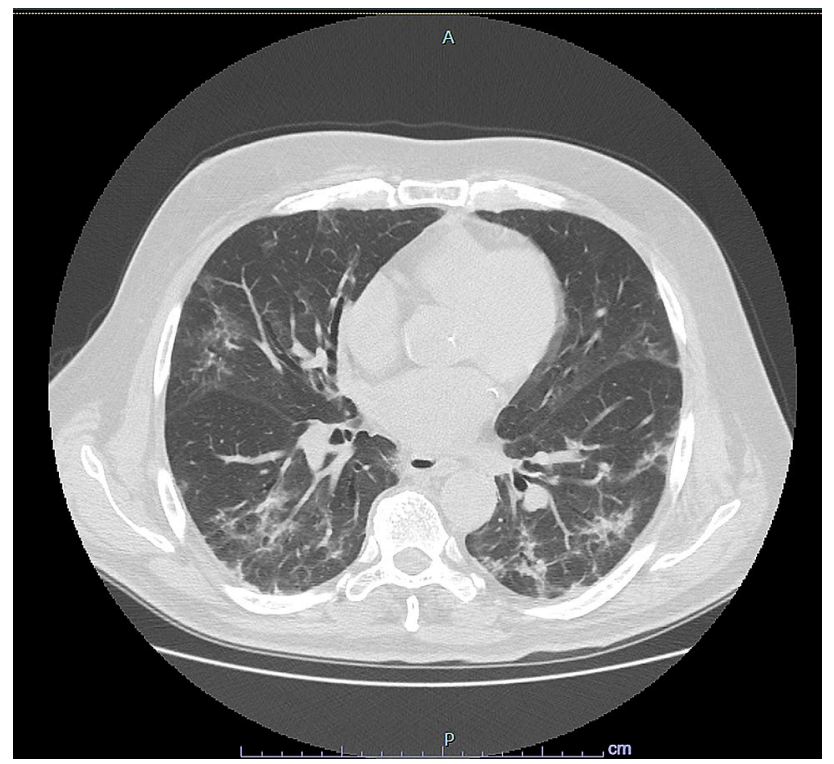

Fig. 1 Chest computer tomography findings at presentation. $C T$ computer tomography. Chest CT showed diffuse ground-glass opacities, with bilateral distribution and multilobar involvement

Although beneficial in terms of platelet count increase and bleeding control, corticosteroids might, however, impact the course of SARS-CoV-2 infection.

The patient received a platelet pool transfusion, with no significant change in the platelet count after $45 \mathrm{~min}$, and methylprednisolone $1 \mathrm{mg} / \mathrm{kg}$, in the hypothesis of a case of ITP [3]. Epistaxis resolved after two platelet pool transfusions and placement of bilateral nasal tampons soaked with tranexamic acid. Because the platelet count persisted very low (Fig. 2), intravenous immunoglobulin (IvIg) (400 mg/ $\mathrm{kg}$ for 5 days) was infused. No response was observed. The patient was admitted to a COVID-19 medical ward and no antiviral treatment was deemed necessary, also in consideration of the concomitant severe thrombocytopenia.

Dr. Clerici and Dr. Di Benedetto. The patient has now been admitted to the medical ward. At this point, further tests must be carried out to ascertain ITP diagnosis and, if this is confirmed, to discriminate between a primary and secondary form. The patient's initial work-up showed COVID19 bilateral interstitial pneumonia, mild anemia associated with severe thrombocytopenia, and two enlarged lymph nodes in the left axillary region. Four possible causes of thrombocytopenia can thus be hypothesized in our patient: SARS-CoV-2 infection, a hematologic malignancy impairing megakaryopoiesis, a lymphoproliferative disorder with accompanying secondary ITP, and primary ITP.

Given the patient's age, we performed a bone marrow biopsy, which revealed a slight increase in megakaryocytes, compatible with the diagnosis of ITP. HCV and HIV antibodies, an autoimmune panel including ANAs and APLAs

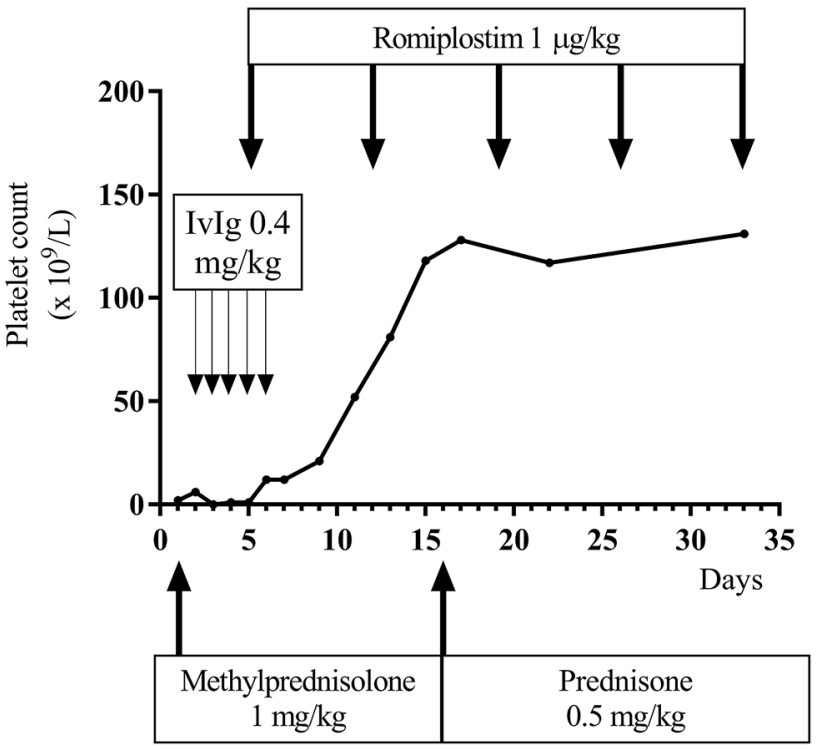

Fig. 2 Changes of platelet count over days of treatment. The patient received intravenous methylprednisolone $(1 \mathrm{mg} / \mathrm{kg})$ from days 1 to 15 and oral prednisone $0.5 \mathrm{mg} / \mathrm{kg}$ from day 16 until now; intravenous immunoglobulin $(400 \mathrm{mg} / \mathrm{kg}$ ) from days 2 to 6 . Romiplostim $(1 \mu \mathrm{g} /$ $\mathrm{kg}$ ) was administered on days 5, 12, 19 and 26

were negative, as well as the search for the fecal antigen of Helicobacter pylori. Because of the incidental findings on the chest CT, paraneoplastic ITP was hypothesized. A whole-body CT scan confirmed the presence of two left axillary enlarged lymph nodes, which displayed moderate contrast enhancement (maximum SUV 3.3) on the following PET scan. After five days of treatment with corticosteroids associated with IvIg, the platelet count was still severely low. Wet purpura and epistaxis persisted, with findings of hemosinus on the CT scan.

Dr. Bertinato and Dr. Caberlon. Although it cannot be excluded that SARS-CoV-2 infection was responsible for the onset of ITP in this patient, the suspicion of an underlying lymphoproliferative disorder made the diagnosis of paraneoplastic ITP at least equally likely. In fact, unresponsiveness to first-line treatment is common in secondary ITP $[4,5]$, whereas there are insufficient data regarding the impact of SARS-CoV-2 on ITP onset, response to first- and secondline treatments and balance between bleeding and thrombotic diatheses. The patient is now unresponsive to first-line treatment: the need of a second-line treatment is unquestionable, whereas the choice of the drug is complicated by the ongoing SARS-CoV-2 infection. The commonest second-line treatment options for ITP include thrombopoietin receptor agonists (TPO-RAs) and Rituximab. Both are safe and effective, although they imply some known side effects, namely liver toxicity and increase in thrombotic risk for TPO-RAs, and immunosuppression for Rituximab. In this patient, the benefits of a rapid increase in platelet count must 
be weighed against the risk of deterioration of the ongoing viral infection, of superimposed hospital-acquired infections, of liver impairment, and of venous thromboembolic events, which might be favored by ITP itself [6,7], the treatment with a TPO-RA [8], the suspected presence of a neoplasm, the length of hospitalization and SARS-CoV-2 infection [9, 10]. The impact of the anti-CD20 activity of Rituximab on the course of SARS-CoV-2 infection in a patient on steroid treatment was unknown and particularly worrisome given the crucial role of humoral immunity in infection contrast $[11,12]$.

Despite the favorable course of SARS-CoV-2 infection (no need for oxygen therapy and sustained apyrexia), treatment with Rituximab was avoided and Romiplostim at the dosage of $1 \mu \mathrm{g} / \mathrm{kg}$ was administered. The platelet count increased from $1 \times 10^{9} / \mathrm{L}$ to $52 \times 10^{9} / \mathrm{L}$ and $118 \times 10^{9} / \mathrm{L}$ 1 week and 10 days after the first dose of Romiplostim. Considering the difficult glycemic control of the patient, corticosteroid treatment was rapidly tapered. Thereafter the platelet count stabilized above $100 \times 10^{9} / \mathrm{L}$ and liver function tests remained within the normal range. The patient developed no complications attributable to SARS-CoV-2 infection, subsequent chest imaging showed improvement of the described ground-glass opacities, and viral clearance was reached after 32 days from initial presentation, in line with available published data [13]. Moreover, the patient showed neither signs nor symptoms of thrombotic complications. The patient underwent the procedure of left axillary lymphadenectomy with a PLT count of $167 \times 10^{9} / \mathrm{L}$ and no pathological bleeding; the histological appearance of the lymph node was compatible with classical Hodgkin's lymphoma, nodular sclerosis subtype. The patient has now been started on specific chemotherapy.

Dr. Birocchi and Dr. Podda. We described a patient with ITP associated with COVID-19 and a newly diagnosed Hodgkin's lymphoma.

The management of immune-mediated diseases such as immune thrombocytopenia (ITP) during the COVID-19 outbreak is challenging. In fact, the consequences of treatments which interfere with the immune system response to infection are unknown. ITP is an immune-mediated acquired hemorrhagic disorder characterized by increased peripheral platelet destruction and impaired compensatory platelet production. Available treatments target the processes of immune-mediated platelet clearance and defective megakaryocytopoiesis. Immunosuppressant treatments aimed at reducing antibody production, such as corticosteroids and Rituximab, are routinely used in ITP [3]. On the other hand, TPO-RAs have been developed to boost platelet production in the bone marrow, so as to increase platelet count. As with all viral infections, humoral immunity plays a crucial role in ending SARS-CoV-2 infection [11, 12]. The historical cornerstone of ITP treatment, corticosteroids and Rituximab, may interfere with this process (Table 1). Moreover, COVID-19infection is associated with an increased thrombotic risk $[9,10]$. This may add to the increase in thrombotic risk posed by TPO-RAs, which are currently preferred as second-line treatment in non-chronic cases of ITP [14]. Lastly, the presence of a previously unknown malignant neoplasm furtherly increases patient complexity. In fact, an adequate platelet count is necessary to undergo invasive procedures, such as lymphadenectomy, and chemotherapy.

Table 1 Facing the choice of ITP treatment in SARS-CoV-2 positive patients

\begin{tabular}{|c|c|c|c|c|}
\hline & $\begin{array}{l}\text { Possible harms and limita- } \\
\text { tions }\end{array}$ & $\begin{array}{l}\text { Possible benefits and advan- } \\
\text { tages }\end{array}$ & $\begin{array}{l}\text { Time to platelet count } \\
\text { improvement }^{\mathrm{a}}\end{array}$ & Duration of treatment effect ${ }^{\mathrm{a}}$ \\
\hline Corticosteroids & $\begin{array}{l}\text { Immunosuppression } \\
\text { Impairment of immune } \\
\text { response to SARS-CoV-2 } \\
\text { infection } \\
\text { Increase in the risk of second- } \\
\text { ary infections }\end{array}$ & $\begin{array}{l}\text { Possibility of outpatient } \\
\text { administration, short } \\
\text { courses of treatment and } \\
\text { rapid tapering }\end{array}$ & Several days to several weeks & $\begin{array}{l}\text { Months (depending on active } \\
\text { principle, tapering and indi- } \\
\text { vidual response) }\end{array}$ \\
\hline IvIg & In-hospital administration & $\begin{array}{l}\text { Quick increase in platelet } \\
\text { count } \\
\text { No foreseeable contraindi- } \\
\text { cations regarding SARS- } \\
\text { CoV-2 infection }\end{array}$ & $\begin{array}{l}\text { Many respond in } 24 \mathrm{~h} \text {; typi- } \\
\text { cally } 2-4 \text { days }\end{array}$ & $\begin{array}{l}\text { Platelet count returns to pre- } \\
\text { treatment levels } 2-4 \text { weeks } \\
\text { after treatment }\end{array}$ \\
\hline Rituximab & $\begin{array}{l}\text { Immunosuppression } \\
\text { In-hospital administration }\end{array}$ & & $1-8$ weeks & $\begin{array}{l}\text { Sustained response }>3-5 \text { years } \\
\text { in } 15-20 \% \text { of responders }\end{array}$ \\
\hline TPO-RAs & $\begin{array}{l}\text { Increase in thrombotic risk } \\
\text { Hepatotoxicity }\end{array}$ & $\begin{array}{l}\text { No foreseeable contraindica- } \\
\text { tions regarding the immune } \\
\text { response to SARS-CoV-2 } \\
\text { infection }\end{array}$ & $1-4$ weeks & $\begin{array}{l}\text { Years with continual adminis- } \\
\text { tration of the drug }\end{array}$ \\
\hline
\end{tabular}

${ }^{a}$ Adapted from the International consensus report on the investigation and management of primary immune thrombocytopenia (Blood 2009, https://doi.org/10.1182/blood-2009-06-225565) 
Access to surgery and outpatient treatment is troublesome for COVID-19 patients, and lymphoproliferative disorders pose a risk of infection, thrombosis and poorer response to ITP treatment [4].

In the face of a scarcely understood and potentially lifethreatening viral infection, the choice of ITP treatment may appear cumbersome. Presently, although the immune response to COVID-19 is not well understood, the development of neutralizing anti-viral $\mathrm{T}$ cell and humoral immunity appears to play a crucial role in ending the disease. Thus, the use of steroids and Rituximabis not a simple choice. The role of corticosteroid treatment in COVID-19 pneumonia remains controversial [15]; despite the potential drawbacks, this course of treatment appeared the safest option for our patient. It was nevertheless decided to opt for methylprednisolone instead of high-dose dexamethasone, to minimize the burden of adverse effects. IvIg represents a safe option, especially in the need for a quick increase in platelet count, although the induced increase in platelet count lasts for only 3-4 weeks. [3] In our patient, ITP was unresponsive to both steroids and IvIg, which is compatible with secondary ITP [4]. The choice of second-line treatment in the COVID19 era may, however, be simplified. The use of Rituximab requires caution, whereas the use of TPO-Rasis quite effective and supported by the latest evidence [7, 8], thus it appears as the second-line treatment of choice for ITP [14]. A potential side effect is the thrombotic risk, which would add to that induced by COVID-19 itself, and venous thrombo-embolism prophylaxis cannot be prescribed in patients with severe thrombocytopenia and ongoing bleeding. Finally, for newly diagnosed or persistent ITP, splenectomy is not recommended and access to surgery during the COVID-19 pandemic can be problematic.

A practical guidance published at the beginning of June 2020 [16] recommends steroids as the first line of treatment in COVID-19 positive patients and advises not to administer Rituximab; as for TPO-RAs, worries concerning hepatotoxicity and the increase in thrombotic risk have been expressed. A section on FAQs on COVID-19 and ITP on the ASH website [17] was more encouraging towards the use of TPO-RAs, although IvIg was the recommended first line of treatment. In a recent French study, 14 patients with profound thrombocytopenia and severe bleeding manifestations due to COVID-19-associated ITP were described [18]. Patients treated with standard therapy, steroids and IvIg adding a TPO-RA in two cases, had a favorable outcome in most cases. These data are consistent with our results. In fact, in our experience, the combination of corticosteroid treatment associated with IvIg and a TPO-RA didn't impair the patient's chances of recovery from COVID-19 pneumonia; we recorded none of the foreseeable complications such as worsening of SARS-CoV-2 infection, thrombotic events, superinfection and hepatotoxicity.
Author contributions $\mathrm{EB}, \mathrm{CD}, \mathrm{SB}$ and $\mathrm{SC}$ provided clinical data regarding the case report and revised the manuscript. GMP and $\mathrm{BC}$ wrote and edited the manuscript. MC supervised patient management and revised the manuscript. GMP made the figures.

\section{Compliance with ethical standards}

Conflict of interest The authors declare no competing financial interests.

Human and animal rights statement Procedures followed were in accordance with the ethical standards of the responsible committee on human experimentation (institutional and national) and with the Helsinki Declaration of 1975, as revised in 2000 and 2008.

Informed consent We obtained written informed consent from the patient.

\section{References}

1. Huang C, Wang Y, Li X et al (2020) Clinical features of patients infected with 2019 novel coronavirus in Wuhan, China. Lancet 395(10223):497-506. https://doi.org/10.1016/S0140 $-6736(20) 30183-5$

2. Zulfiqar AA, Lorenzo-Villalba N, Hassler P, Andrès E (2020) Immune thrombocytopenic purpura in a patient with covid-19. N Engl J Med 382(18):E43. https://doi.org/10.1056/NEJMc2010472

3. Provan D, Arnold DM, Bussel JB et al (2019) Updated international consensus report on the investigation and management of primary immune thrombocytopenia. Blood Adv 3(22):3780-3817. https://doi.org/10.1182/bloodadvances.2019000812

4. Alvarez-rom T, Pascual C, Fern F, Mart V, Alonso A (2017) Use of eltrombopag for secondary immune thrombocytopenia in clinical practice. Br J Haematol 178:959-970. https://doi.org/10.1111/ bjh. 14788

5. Podda GM, Fiorelli EM, Birocchi S et al (2020) Treatment of immune thrombocytopenia (ITP) secondary to malignancy: a systematic review. Platelets. https://doi.org/10.1080/09537 104.2020.1822521

6. Rodeghiero F (2016) Is ITP a thrombophilic disorder? Am J Hematol 91(1):39-45. https://doi.org/10.1002/ajh.24234

7. Ruggeri M, Tosetto A, Palandri F et al (2014) Thrombotic risk in patients with primary immune thrombocytopenia is only mildly increased and explained by personal and treatment-related risk factors. J Thromb Haemost 12(8):1266-1273. https://doi. org/10.1111/jth. 12636

8. Birocchi S, Podda GM, Manzoni M, Casazza G, Cattaneo M (2020) Thrombopoietin receptor agonists for the treatment of primary immune thrombocytopenia: a meta-analysis and systematic review. Platelets 00(00):1-11. https://doi.org/10.1080/09537 104.2020.1745168

9. McGonagle D, O'Donnell JS, Sharif K, Emery P, Bridgewood C (2020) Immune mechanisms of pulmonary intravascular coagulopathy in COVID-19 pneumonia. Lancet Rheumatol 2019(20):19. https://doi.org/10.1016/S2665-9913(20)30121-1

10. Violi F, Pastori D, Cangemi R, Pignatelli P, Loffredo L (2020) Hypercoagulation and antithrombotic treatment in coronavirus 2019: a new challenge. Thromb Haemost 120(6):949-956. https ://doi.org/10.1055/s-0040-1710317

11. Tay MZ, Poh CM, Rénia L, MacAry PA, Ng LFP (2020) The trinity of COVID-19: immunity, inflammation and intervention. 
Nat Rev Immunol 20(6):363-374. https://doi.org/10.1038/s4157 7-020-0311-8

12. Catanzaro M, Fagiani F, Racchi M, Corsini E, Govoni S, Lanni C (2020) Immune response in COVID-19: addressing a pharmacological challenge by targeting pathways triggered by SARS-CoV-2. Signal Transduct Target Ther 5(1):84. https://doi. org/10.1038/s41392-020-0191-1

13. Zhou B (2020) The duration of viral shedding of discharged patients with severe COVID-19. Clin Infect Dis. https://doi. org/10.1093/cid/ciaa451

14. Neunert C, Terrell DR, Arnold DM et al (2019) American Society of Hematology 2019 guidelines for immune thrombocytopenia. Blood Adv 3(23):3829-3866. https://doi.org/10.1182/bloodadvan ces. 2019000966

15. Fadel R, Morrison AR, Vahia A et al (2020) Early short course corticosteroids in hospitalized patients with COVID-19. Clin Infect Dis. https://doi.org/10.1093/cid/ciaa601

16. Pavord S, Thachil J, Hunt B et al (2020) Practical guidance for the management of adults with Immune thrombocytopenia during the COVID-19 pandemic. Br J Haematol. https://doi.org/10.1111/ bjh. 16775
17. Bussel J, Cines D, Cooper N et al. https://www.hematology.org/ covid-19/covid-19-and-itp

18. Mahévas M, Moulis G, Andres E et al (2020) Clinical characteristics, management and outcome of COVID-19-associated immune thrombocytopenia: a French multicentre series. Br J Haematol 190(4):e224-e229. https://doi.org/10.1111/bjh.17024

Publisher's Note Springer Nature remains neutral with regard to jurisdictional claims in published maps and institutional affiliations. 